Article

\title{
Continuous Microalgal Cultivation for Antioxidants Production
}

\author{
Jenny Fabiola López-Hernández ${ }^{1}$, Pedro García-Alamilla ${ }^{2}$, Diana Palma-Ramírez ${ }^{3}$, \\ Carlos Alfonso Álvarez-González ${ }^{1}$ (D), Juan Carlos Paredes-Rojas ${ }^{3}$ (D) \\ and Facundo J. Márquez-Rocha $4, *$ (D) \\ 1 Academic Division of Biological Sciences, Universidad Juárez Autónoma de Tabasco, Villahermosa, \\ Tabasco 86150, Mexico; jflh23@hotmail.com (J.F.L.-H.); alvarez_alfonso@hotmail.com (C.A.Á.-G.) \\ 2 Academic Division of Agriculture and Livestock Science, Universidad Juárez Autónoma de Tabasco, Centro, \\ Tabasco 86280, Mexico; pedro.garciaa@ujat.mx \\ 3 Mexican Center for Cleaner Production, CDMX, Instituto Politécnico Nacional, \\ Ciudad de México 07738, Mexico; dpalmar@ipn.mx (D.P.-R.); paredesrojasjc@gmail.com (J.C.P.-R.) \\ 4 Mexican Center for Cleaner Production, Tabasco Unit, Instituto Politécnico Nacional, Cunduacán, \\ Tabasco 86691, Mexico \\ * Correspondence: fjmrocha97@gmail.com
}

Academic Editors: Ana R. Díaz-Marrero and José Javier Fernández Castro

Received: 5 August 2020; Accepted: 8 September 2020; Published: 11 September 2020

check for updates

\begin{abstract}
Microalgae, including cyanobacteria, represent a valuable source of natural compounds that have remarkable bioactive properties. Each microalga species produces a mixture of antioxidants with different amounts of each compound. Three aspects are important in the production of bioactive compounds: the microalga species, the medium composition including light supplied and the photobioreactor design, and operation characteristics. In this study, the antioxidant content and productivity performance of four microalgae were assessed in batch and continuous cultures. Biomass productivity by the four microalgae was substantially enhanced under continuous cultivation by 5.9 to 6.3 times in comparison with batch cultures. The energetic yield, under the experimental

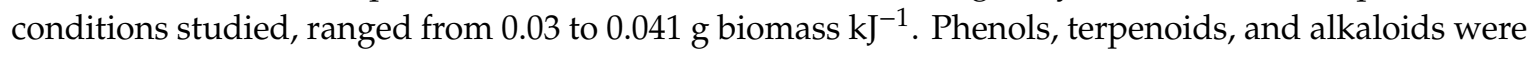
produced by Spirulina platensis, Isochrysis galbana, and Tetraselmis suecica, whereas tocopherols and carotenoids were produced by the four microalgae, except for phycocyanin and allophycocyanin, which were only produced by S. platensis and Porphyridium cruentum. The findings demonstrate that the continuous cultivation of microalgae in photobioreactors is a convenient method of efficiently producing antioxidants.
\end{abstract}

Keywords: antioxidants; phenols; tocopherols; phycocyanin; continuous cultivation; microalgae

\section{Introduction}

Microalgae are a promising group of microorganisms that produce novel compounds, known as secondary metabolites. Value-added microalgal products are associated with the health and cosmetics industries, unrestricted products produced for medical care, and the aquaculture industry [1,2]. Cure from cancer is the goal of cancer therapy. Many deaths in women are due to cervical, stomach, and breast cancers; the demand for anticancer agents from natural sources has increased for antitumor therapy due to the less severe or lack of secondary effects of these treatments [3]. Various microalga species have been reported to produce nutraceuticals, renewable-energy-related compounds, $\beta$-carotene, astaxanthin, polyunsaturated fatty acids (PUFAs), and biocolorants; all these compounds are accumulated during growth and are produced for different applications such as health- and food-based products [1], wastewater treatment, aquaculture, etc. [2,4]. 
The microalgae are primary marine producers consumed by many other marine organisms throughout the food chain. Recent studies showed that some species of algae contain large amounts of antioxidants, such as vitamin E, pigments, and phenolic compounds. Natural antioxidants found in algae may play important roles against various diseases and aging processes by protecting the cells against oxidative damage, including DNA and protein oxidative damage, through high scavenging activity $[5,6]$. The oxidative mechanism involves an important flow of free radicals following a chain of reactions that occurs in all photosynthetic microorganisms. Oxidation reactions produce free radicals that eventually cause oxidation of key molecules, such as protein and DNA breakage, cell damage, or cell death. For this reason, it is important to maintain a cellular balance of free-radical intermediates with antioxidants produced by the cells, especially those that remove the free-radical intermediates, preventing harmful oxidative reactions [7]. Microalgae produce free-radical scavenging compounds, such as phenols, vitamins, pigments, and enzymes. These compounds can also exhibit antibacterial, antitumor, anticarcinogenic, and anti-inflammatory activities in cells [8]. Red, brown, and green algae, as well as cyanobacteria, display high radical scavenging activities [9]. The main antioxidants found in algae are vitamins $C$ and E [10], carotenoids ( $\beta$ - and $\alpha$-carotene, zeaxanthin, and neoxanthin), chlorophylls, [11,12], and phenols [13]. The tocopherols show antioxidant activity, providing an important function in the electron transport system, which is a key process in photosynthetic organisms. Other important scavenging elements include enzymes that have antioxidant activity, which are divided into two categories: primary and secondary defense. The primary defense enzymes neutralize free radicals; these include enzymes such as glutathione peroxidase, catalase, and superoxide dismutase. In coordination, they neutralize highly reactive species to less reactive species. The second category comprises enzymes that drive electronic flow during metabolism, e.g., the glutathione reductase reduces glutathione to its reduced form and this recycling continues neutralizing free radicals. Glucose-6-phosphate regenerates NADPH from its oxidized form. Other important nonenzymatic antioxidants include vitamins (A, C, and E), cofactors (Q10), minerals (selenium, zinc), peptides (glutathione), and phenolic and nitrogenate compounds [14]. Metabolites such as phenols, folate, folic acid, and other pigments can produce beneficial effects on health related to hypercholesterolemia, cardiovascular diseases, viral infections, and cancer [7]. Plant antioxidants include a variety of compounds, including tocopherols, ascorbic acid, resveratrol, flavonoids, flavanol, and flavanones, but plants are not the only organisms that produce these compounds; microalgae, as photosynthetic organisms, produce many of these and other compounds with antioxidant properties $[15,16]$. One advantage of producing antioxidants from microalgae is its cultivation versatility and many technological improvements can be applied since strain selection improving the bioprocesses is important for enhancing a product.

Phycobiliproteins (PBPs) are photosynthetic pigments found in cyanobacteria, rhodophytes, cryophytes, and glaucophytes. PBPs include phycocyanin (PC), allophycocyanin (APC), and phycoerythrin (PE). PC is a fluorescent protein with a prosthetic group (bilins) linked to cysteine residues and a water-soluble compound, with a molecular weight of $586.7 \mathrm{~g} \mathrm{~mol}^{-1}$. Phycocyanin is a natural product with important productive and bioactive advantages for food quality and in the pharmaceutical and cosmetic industries. The use of PC has been recently reported as a natural colorant and an important antioxidant protector. The health and nutraceutical effects of PC include neuroprotective, anti-inflammatory, anticancer, and hepatoprotective properties, which are properties linked to the oxidative mechanism in the photosynthesis system in vivo [17]. Santiago et al. demonstrated that PC has potent antioxidant and synergic activities connected to effectively scavenging hydrogen peroxide [18]. The chemical structure of its chromophore is similar to biliverdin, which protects against oxidative stress and normalizes renal oxidative stress markers and the expression of $\mathrm{NAD}(\mathrm{P}) \mathrm{H}$ oxidase components. PC inhibited NADPH independent of the superoxide production in cultured renal mesangial cells [19]. Other metabolites, such as polyphenols, folate, folic acid, and other pigments, can beneficially affect health, including hypercholesterolemia, cardiovascular diseases, viral infections, and cancer [7]. Chen et al. 
reported an engineering strategy to simultaneously produce PC with a productivity of $0.13 \mathrm{~g} \mathrm{~L}^{-1} \mathrm{~d}^{-1}$ and a $\mathrm{CO}_{2}$ consumption of $1.58 \mathrm{~g} \mathrm{~L}^{-1} \mathrm{~d}^{-1}$ with Spirulina platensis [20].

Two kinds of photobioreactors exist that produce microalgae biomass: open and closed photobioreactor designs. The dynamics of the cultures allow them to be produced either in batches or continuously, working under natural or artificial light irradiance. However, open systems have two disadvantages: contamination with bacteria and light supply. Additionally, the general cell density is low and only few microalgae species are suitable for this production mode due to contamination. Closed systems are an alternative to producing highly valuable compounds such as antioxidants. The control of all operational parameters is more easily accomplished in closed systems, but costs are high. One alternative to enhancing biomass density and production is operating photobioreactors during continuous production. One difficulty to be overcome is the low growth rate of microalgae that may cause complications in achieving continuous cultivation before washout of the cells [17]. In the present study, antioxidants production by microalgae was assessed in continuous mode operation in a photobioreactor (PBR).

\section{Results}

\subsection{Growth Analyses in Batch and Continuous Cultivation}

The growth profiles were analyzed in the batch and continuous cultures of four microalgae. The growth performance of four microalgae in batch cultivation is shown in Figure 1. Specific growth rates were calculated by the Gompertz growth equation, which were found to be $0.53,0.49,0.51$, and $1.1 \mathrm{~d}^{-1}$ for Spirulina platensis, Isochrysis galbana, Tetraselmis suecica, and Porphyridium cruentum, respectively. Biomass concentration and biomass productivity values are summarized in Table 1. The biomass concentrations in batch cultures were 3, 1.5, 1.8, $2.1 \mathrm{~g} \mathrm{~L}^{-1}$ for S. platensis, I. galbana, T. suecica, and P. cruentum, respectively (Table 1 ). The growth of microalgae depends on the culture conditions such as medium composition, hydrodynamics in the bioreactor, and light irradiation that reaches every cell. By comparing all data of the Gompertz growth parameters among all microalgae, $\mu$ (growth specific rate) and maximum biomass density were different for all strains (Table 1).

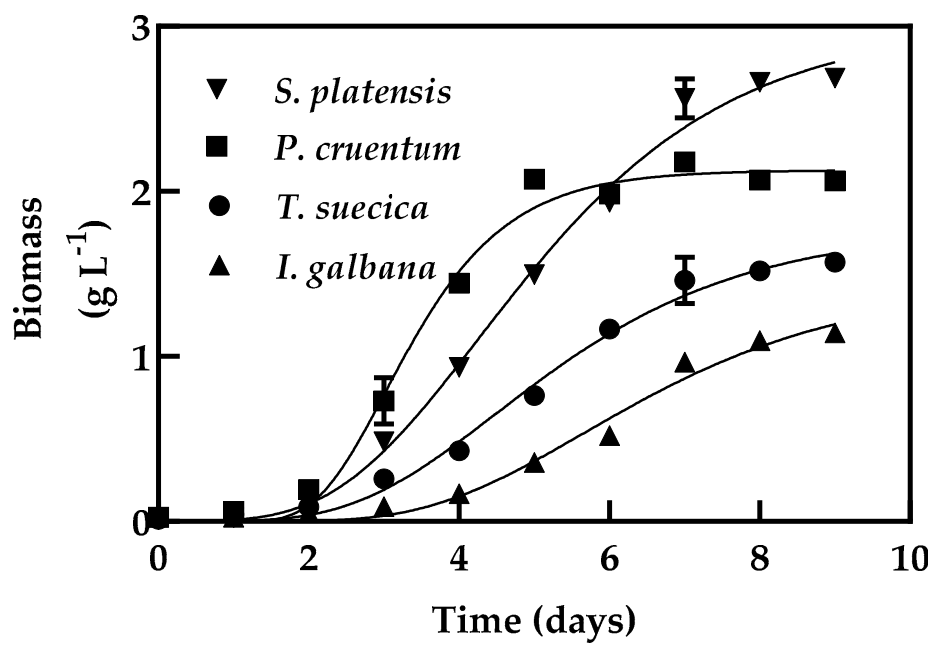

Figure 1. Growth of microalgae in batch cultures. Microalgae were cultivated in batch operation mode in a photobioreactor at $200 \mathrm{rpm}$, at $30{ }^{\circ} \mathrm{C}, 39.63 \mathrm{~kJ} \mathrm{~d}^{-1}$ of light supplied, and $1 \mathrm{~L}$ working volume. Each point is the mean of 3 replicates. 
Table 1. Growth parameters. Values obtained in bath cultivation for 9 days' growth.

\begin{tabular}{cccc}
\hline Strain & $\boldsymbol{\mu}$ & Biomass & Biomass Productivity \\
\hline & $\mathbf{d}^{\mathbf{- 1}}$ & $\mathbf{g ~ L}^{\mathbf{- 1}}$ & ${\text { g biomass } \mathbf{L}^{\mathbf{- 1}} \mathbf{d}^{\mathbf{- 1}}}$ \\
\hline Spirulina platensis & $0.53^{\mathrm{a}}$ & $3.02^{\mathrm{e}}$ & $0.34^{\mathrm{i}}$ \\
Isochrysis galbana & $0.49^{\mathrm{b}}$ & $1.45^{\mathrm{f}}$ & $0.16^{\mathrm{j}}$ \\
Tetraselmis suecica & $0.51^{\mathrm{c}}$ & $1.78^{\mathrm{g}}$ & $0.20^{\mathrm{k}}$ \\
Porphyridium cruentum & $1.10^{\mathrm{d}}$ & $2.13^{\mathrm{h}}$ & $0.24^{1}$ \\
\hline
\end{tabular}

Note: Different letters indicate significant differences; $39.63 \mathrm{~kJ} \mathrm{~d}^{-1}$ of light supplied. Values are the means of 3 replicates $(p<0.05)$.

The batch cultures reached maximum cell concentrations over nine days of cultivation; maximum cell concentration indicates the change from batch to continuous cultivation. The dilution rate, which corresponds to the growth rate in continuous culture, was fixed at $0.6 \mathrm{~d}^{-1}$ for S. platensis, I. galbana, T. suecica, and P. cruentum. Different light intensities were supplied $\left(16.27,21.26,30.42\right.$, and $\left.39.63 \mathrm{~kJ} \mathrm{~d}^{-1}\right)$. The biomass concentrations of the four microalgae increased as light intensity increased in continuous culture (Table 2). The biomass concentration under all light intensities in continuous cultures were significantly different for all microalgae used. Biomass concentration in descending order at a light intensity of $39.63 \mathrm{~kJ} \mathrm{~d}^{-1}$ was: $3.35>2.63>1.93>1.58 \mathrm{~g}$ biomass $\mathrm{L}^{-1}$ for S. platensis, P. cruentum, T. suecica, and I. galbana, respectively (Table 2), in comparison with biomass in bath cultures: $3.0>2.1>$ $1.8>1.5 \mathrm{~g} \mathrm{~L}^{-1}$, respectively, for the same light irradiance $\left(39.63 \mathrm{~kJ} \mathrm{~d}^{-1}\right)$.

Table 2. Biomass accumulation: biomass concentration of microalgae at different light intensities supplied to continuous cultures.

\begin{tabular}{ccccc}
\hline $\mathbf{I}_{\mathbf{0}} \mathbf{A}$ & S. platensis & I. galbana & T. suecica & P. cruentum \\
\hline$\left(\mathrm{kJ} \mathrm{d}^{-1}\right)$ & & \multicolumn{2}{c}{ g biomass L $^{-1}$} \\
16.27 & $1.68^{\mathrm{a}}$ & $0.43^{\mathrm{e}}$ & $0.68^{\mathrm{i}}$ & $1.15^{\mathrm{m}}$ \\
21.26 & $2.18^{\mathrm{b}}$ & $0.65^{\mathrm{f}}$ & $0.93^{\mathrm{j}}$ & $1.55^{\mathrm{n}}$ \\
30.42 & $2.68^{\mathrm{c}}$ & $1.10^{\mathrm{g}}$ & $1.52^{\mathrm{k}}$ & $2.07^{\mathrm{o}}$ \\
39.63 & $3.35^{\mathrm{d}}$ & $1.58^{\mathrm{h}}$ & $1.93^{\mathrm{l}}$ & $2.63^{\mathrm{P}}$ \\
\hline
\end{tabular}

Note: Different letters indicate significant differences in the means of 3 replicates $(p<0.05) . \mathrm{I}_{0} \mathrm{~A}$ is defined as the energy supplied from light to a surface area per unit of time.

Biomass productivity (XVD (g biomass $\mathrm{L}^{-1} \mathrm{~d}^{-1}$ ), where $\mathrm{X}$ is biomass $(\mathrm{g}), \mathrm{V}$ is working volume $\left(\mathrm{L}^{-1}\right)$, and $\mathrm{D}$ is dilution rate $\left.\left(\mathrm{d}^{-1}\right)\right)$ obtained in terms of total light supplied $\left(\mathrm{I}_{0} \mathrm{~A}\left(\mathrm{~kJ} \mathrm{~d} \mathrm{~d}^{-1}\right)\right.$ energy supplied from light to a surface area per unit of time) is shown in Figure 2. The productivity of biomass at a light intensity of $39.63 \mathrm{~kJ} \mathrm{~d}^{-1}$ in batch culture was $0.34,0.24,0.2$, and $0.16 \mathrm{~g}$ biomass $\mathrm{L}^{-1} \mathrm{~d}^{-1}$ (Table 1 ) and 2.01, 1.58, 1.16, and 0.95, g biomass $\mathrm{L}^{-1} \mathrm{~d}^{-1}$, for S. platensis, P. cruentum, T. suecica, and I. galbana, respectively, in continuous cultivation (Figure 2). Comparison of the biomass productivity (XVD) though linear regression analysis of each microalga showed statistically significant differences with increasing light intensity. The productivity increase of biomass concentration was 5.9-6.6 times higher in continuous cultures, which may support the final quantity of antioxidants produced, as shown below. The energetic yield of the produced biomass for the supplied light energy varied according to the strain: $0.041,0.037,0.033$, and $0.030 \mathrm{~g}$ biomass produced per $\mathrm{kJ}$ for S. platensis, P. cruentum, T. suecica, and I. galbana, respectively, and a yield of conversion efficiency $\left(\mathrm{Y}_{\mathrm{ce}}\right.$, luminous energy to chemical energy) of $1.04,0.95,0.83$, and 0.75 , respectively $\left(-\Delta \mathrm{Ho} \times \mathrm{Y}_{\mathrm{kcal}}\right.$; enthalpy change for $\mathrm{O}_{2}=106 \mathrm{kcal} \mathrm{mol}^{-1} \mathrm{O}_{2}$ ). 


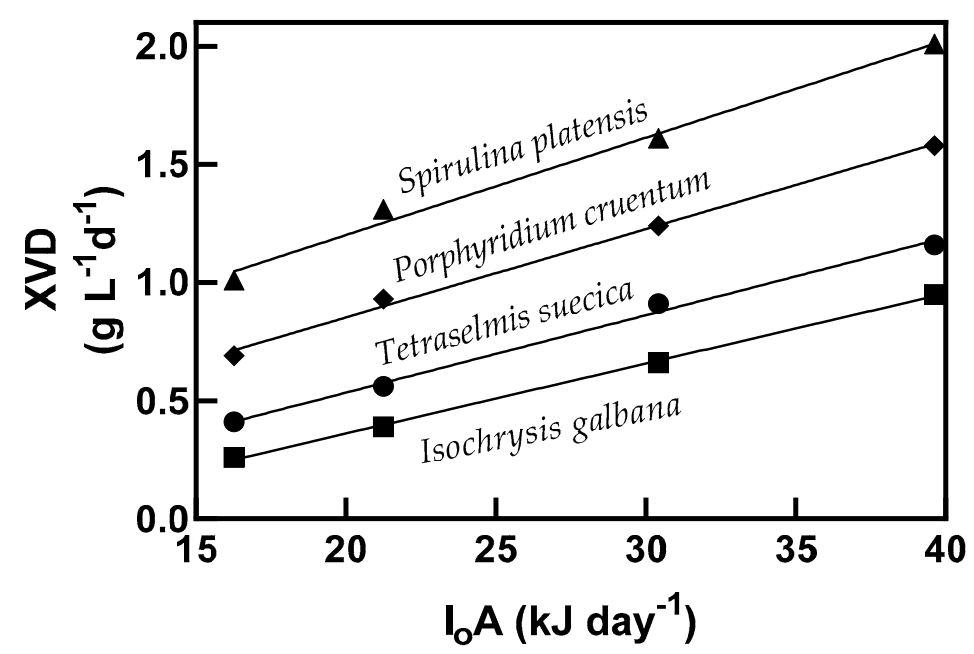

Figure 2. The biomass produced in steady state condition at $D$ (dilution rate) $=0.6 \mathrm{~d}^{-1}$ for each energy supplied in continuous cultures of S. platensis, P. cruentum, T. suecica, and I. galbana.

\subsection{Antioxidant Production in Batch Culture}

Total phenols, alkaloids, and terpenoids content were measured in S. platensis, I. galbana, and T. suecica during batch cultivation (Table 3). All compounds were produced by the microalgae in significantly different amounts $(p<0.05)$, except for alkaloids between I. galbana and T. suecica, where no significant differences were observed. Phenol, alkaloids, and terpenoids were more abundant in S. platensis than the others; these compounds accumulated during growth.

Table 3. Antioxidants concentration in batch cultures. Phenols, alkaloids, and terpenoids content in S. platensis, I. galbana, and T. suecica in batch cultures with a supplied light intensity of $39.63 \mathrm{~kJ} \mathrm{~d}^{-1}$ in 9 days' culture.

\begin{tabular}{cccc}
\hline Strain & Phenols & Alkaloids & Terpenoids \\
\hline \multicolumn{3}{c}{$\mathbf{m g ~ g}^{\mathbf{- 1}}$ biomass } \\
\hline S. platensis & $1.02^{\mathrm{a}}$ & $0.07^{\mathrm{d}}$ & $0.094^{\mathrm{f}}$ \\
I. galbana & $0.47^{\mathrm{b}}$ & $0.05^{\mathrm{e}}$ & $0.081^{\mathrm{g}}$ \\
T. suecica & $0.83^{\mathrm{c}}$ & $0.03^{\mathrm{e}}$ & $0.075^{\mathrm{h}}$ \\
\hline
\end{tabular}

Note: The same letter in each column indicates no significant differences in the means of 3 replicates $(p<0.05)$.

The productivities of phenols, alkaloids, and terpenoids showed significant differences among the three species (Figure 3). The productivity of phenols in S. platensis was four times that of I. galbana and 1.75 times that of T. suecica (Figure 3). Alkaloids and terpenoids also showed significant differences among the three species of microalgae.

Tocopherols $(\alpha, \delta$, and $\gamma)$, carotenoids, superoxide dismutase (SOD), and phycobiliproteins were recorded during batch production in the four microalgae (Table 4). The total tocopherol amount is reported here as the sum of $\alpha, \delta$, and $\gamma$ tocopherols in I. galbana, T. suecica, as well as the sum of $\alpha$ and $\gamma$ tocopherols in S. platensis and P. cruentum. In S. platensis and P. cruentum, $\delta$-tocopherol was not found. A large amount of tocopherol was produced in P. cruentum, with $\alpha$ - and $\gamma$-tocopherol at 80.5 and $104.2 \mu \mathrm{g} \mathrm{g}^{-1}$, respectively. Durmaz et al. reported $106.3 \mu \mathrm{g} \mathrm{g}^{-1}$ biomass for both $\alpha$ - and $\gamma$-tocopherols in P. cruentum [21], which is different from the $185 \mu \mathrm{g} \mathrm{g}^{-1}$ obtained in this study. Figure 4 shows the accumulation of PC and APC in S. platensis during growth. 


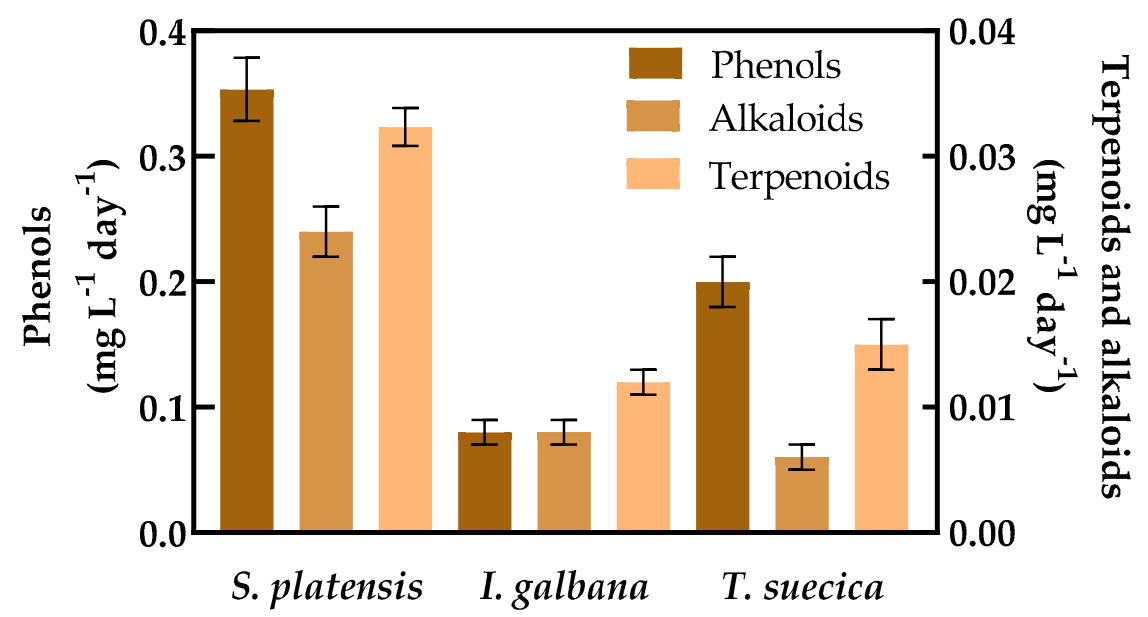

Figure 3. Antioxidant productivities in batch cultures. Phenols, alkaloids, and terpenoids productivities in S. platensis, I. galbana, and T. suecica in batch cultures under a supplied light intensity of $39.63 \mathrm{~kJ} \mathrm{~d}^{-1}$ for 9 days of cultivation. Values are the means of 3 replicates $(p<0.05)$.

Table 4. Antioxidant concentrations in batch culture: tocopherols, carotenoids, phycocyanin (PC), allophycocyanin (APC), and superoxide dismutase (SOD) content in S. platensis, I. galbana, T. suecica, and $P$. cruentum in batch cultures supplied with a light energy of $39.63 \mathrm{~kJ} \mathrm{~d}^{-1}$ for 9 days of culture.

\begin{tabular}{ccccccc}
\hline Strain & Tocopherols & Carotenoids & PC & APC & SOD & SOD \\
\hline & $\mu \mathrm{g} \mathrm{g}^{-1}$ & & $\mathrm{mg} \mathrm{g}^{-1}$ & & $\mathrm{UA} \mathrm{mg}^{-1}$ protein & $\mathrm{UA} \mathrm{g}^{-1}$ biomass $^{\mathrm{c}}$ \\
\hline S. platensis & $120.5^{\mathrm{a}}$ & $3.70^{\mathrm{d}}$ & $198^{\mathrm{g}}$ & $92^{\mathrm{i}}$ & $53.9^{\mathrm{k}}$ & $3541.23^{\mathrm{m}}$ \\
I. galbana & $115.5^{\mathrm{a}}$ & $5.13^{\mathrm{e}}$ & nd & nd & $35.3^{1}$ & $1535.55^{\mathrm{n}}$ \\
T. suecia & $159.8^{\mathrm{b}}$ & $4.71^{\mathrm{f}}$ & nd & nd & $54.6^{\mathrm{k}}$ & $2801.01^{\mathrm{o}}$ \\
P. cruentum & $184.7^{\mathrm{c}}$ & $4.61^{\mathrm{f}}$ & $35.4^{\mathrm{h}}$ & $13.2^{\mathrm{j}}$ & $74.5^{1}$ & $5803.61^{\mathrm{p}}$ \\
\hline
\end{tabular}

The same letter in each column indicates nonsignificant statistical difference in the means of 3 replicates $(p<0.05)$. nd: not determined. UA (activity units).

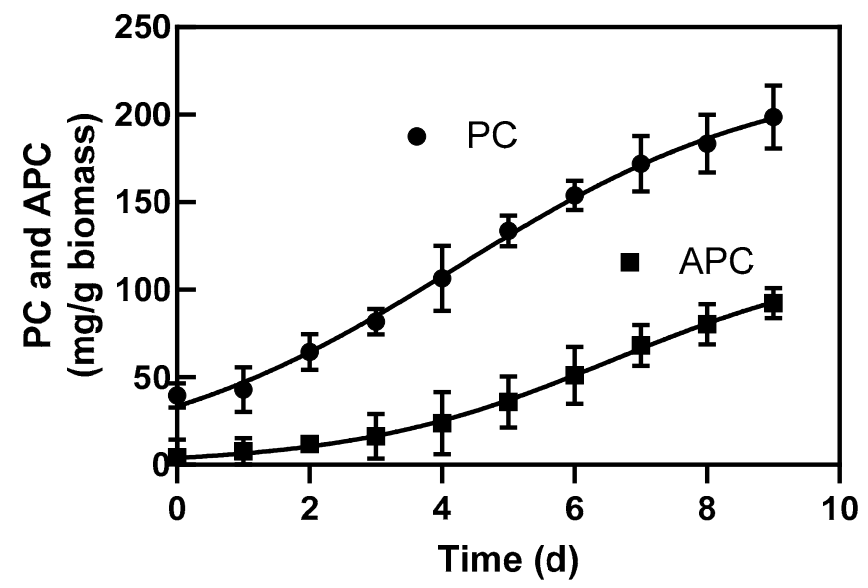

Figure 4. PC and APC formation during growth. Phycocyanin (PC) and allophycocyanin (APC) formation along with the growth of $S$. platensis in batch cultures supplied a light irradiance of $39.63 \mathrm{~kJ} \mathrm{~d}^{-1}$ during 9 days culture.

The productivities of antioxidants in microalgae are shown in Table 5. The productivity of tocopherols in S. platensis and P. cruentum showed no significant differences. Carotenoids, PC, APC, and SOD productivities were statistically different in all microalgae. 
Table 5. Antioxidant productivity in batch cultures. Tocopherols, carotenoids, PC, APC, and SOD productivities in batch cultures with a light irradiance of $39.63 \mathrm{~kJ} \mathrm{~d}^{-1}$ with 9 days of culture.

\begin{tabular}{cccccc}
\hline Strain & Tocopherols & Carotenoids & PC & APC & SOD \\
\hline & $\boldsymbol{\mu} \mathbf{g ~ L}^{-\mathbf{1}} \mathbf{d}^{\mathbf{- 1}}$ & & $\mathbf{m g ~ L}^{\mathbf{- 1}} \mathbf{d}^{\mathbf{- 1}}$ & & $\mathbf{U A ~ L ~}^{\mathbf{- 1}} \mathbf{d}^{\mathbf{- 1}}$ \\
\hline S. platensis & $40.97^{\mathrm{a}}$ & $1.26^{\mathrm{d}}$ & $67.32^{\mathrm{h}}$ & $31.28^{\mathrm{j}}$ & $1204.02^{\mathrm{l}}$ \\
I. galbana & $18.48^{\mathrm{b}}$ & $0.82^{\mathrm{e}}$ & nd & nd & $245.69^{\mathrm{m}}$ \\
T. suecia & $31.96^{\mathrm{c}}$ & $0.94^{\mathrm{f}}$ & nd & nd & $560.20^{\mathrm{n}}$ \\
P. cruentum & $44.33^{\mathrm{a}}$ & $1.11^{\mathrm{g}}$ & $8.50^{\mathrm{i}}$ & $3.17^{\mathrm{k}}$ & $1392.87^{\mathrm{o}}$ \\
\hline
\end{tabular}

The same letter in each column indicates no significant difference in the means of 3 replicates $(p<0.05)$. nd: not determined.

\subsection{Antioxidant Concentration and Productivities in Continuous Culture at Different Light Intensities}

The concentrations of total phenols, terpenoids, and alkaloids were analyzed in continuous cultures of S. platensis, I. galbana, and T. suecica at different light intensities. Total phenols, alkaloids, and terpenoids concentrations were significantly different among the three microalgae $(p<0.05$; Table 6$)$. Phenols, alkaloids, and terpenoids content did not significantly change in any of the microalgae with 16.27 and $21.26 \mathrm{~kJ} \mathrm{~d}^{-1}$ of supplied light intensity (Table 6). By increasing light intensity to $30.42 \mathrm{~kJ} \mathrm{~d}^{-1}$ phenols, alkaloids, and terpenoids content changed significantly in every microalga, except for phenols content in I. galbana. Phenols, alkaloids, and terpenoids content showed significant differences at $39.63 \mathrm{~kJ} \mathrm{~d}^{-1}$ in comparison with the contents of these compounds at 16.27 and $21.26 \mathrm{~kJ} \mathrm{~d}^{-1}$ in every microalga. A significant difference in phenols content was found in S. platensis and I. galbana by changing light intensity from 30.42 to $39.63 \mathrm{~kJ} \mathrm{~d}^{-1}$ (Table 6).

Table 6. Phenol, alkaloids, and terpenoids content of three microalgae in continuous cultures at different light intensities.

\begin{tabular}{cccccccccc}
\hline $\mathbf{I}_{\mathbf{~}} \mathbf{A}$ & \multicolumn{3}{c}{ S. platensis } & \multicolumn{3}{c}{ I. galbana } & \multicolumn{3}{c}{ T. suecica } \\
\hline $\mathbf{k J ~ d}^{\mathbf{1}}$ & \multicolumn{9}{c}{ mg compound $\mathbf{~}^{\mathbf{- 1}}$ biomass } \\
\hline & $\mathrm{A}$ & $\mathrm{B}$ & $\mathrm{C}$ & $\mathrm{A}$ & $\mathrm{B}$ & $\mathrm{C}$ & $\mathrm{A}$ & $\mathrm{B}$ & $\mathrm{C}$ \\
16.27 & $0.96^{\mathrm{a}}$ & $0.076^{\mathrm{d}}$ & $0.091^{\mathrm{f}}$ & $0.38^{\mathrm{i}}$ & $0.049^{\mathrm{k}}$ & $0.077^{\mathrm{m}}$ & $0.81^{\mathrm{o}}$ & $0.030^{\mathrm{q}}$ & $0.068^{\mathrm{s}}$ \\
21.26 & $0.98^{\mathrm{a}}$ & $0.079^{\mathrm{d}}$ & $0.092^{\mathrm{f}}$ & $0.40^{\mathrm{i}}$ & $0.051^{\mathrm{k}}$ & $0.080^{\mathrm{m}}$ & $0.83^{\mathrm{o}}$ & $0.031^{\mathrm{q}}$ & $0.070^{\mathrm{s}}$ \\
30.42 & $1.06^{\mathrm{b}}$ & $0.085^{\mathrm{e}}$ & $0.095^{\mathrm{g}}$ & $0.41^{\mathrm{i}}$ & $0.053^{\mathrm{l}}$ & $0.083^{\mathrm{n}}$ & $0.87^{\mathrm{p}}$ & $0.035^{\mathrm{r}}$ & $0.073^{\mathrm{t}}$ \\
39.63 & $1.12^{\mathrm{c}}$ & $0.082^{\mathrm{e}}$ & $0.096^{\mathrm{g}}$ & $0.45^{\mathrm{j}}$ & $0.055^{1}$ & $0.085^{\mathrm{n}}$ & $0.85^{\mathrm{P}}$ & $0.033^{\mathrm{r}}$ & $0.075^{\mathrm{t}}$ \\
\hline
\end{tabular}

A, phenols; B, alkaloids; $\mathrm{C}$, terpenoids. Identical letters in each column indicate no significant statistical difference in the means of 3 replicates $(p<0.05)$.

The productivity of phenols, alkaloids, and terpenoids in S. platensis, I. galbana, and T. suecica under four different light intensities cultured under continuous cultivation is shown in Figure 5A-C. The three compounds' productivity increased significantly with increasing light intensity in every microalga. Phenol productivity in S. platensis was five times higher than in I. galbana, and more than twice that of T. suecica at a light intensity of $39.63 \mathrm{~kJ} \mathrm{~d}^{-1}$. Phenol productivity increased more than twice in S. platensis, more than four times in I. galbana, and three times than T. suecica with the change in light intensity from 16.27 to $39.63 \mathrm{~kJ} \mathrm{~d}^{-1}$ (Figure 5A). Alkaloid productivity of S. platensis was more than three times that of I. galbana, and more than four times that of T. suecica (Figure 5B). The alkaloid productivity was 2.1 times higher in S. platensis, 4.1 times in I. galbana, and more than three times higher in T. suecica with increasing the light intensity from 16.27 to $37.63 \mathrm{~kJ} \mathrm{~d}^{-1}$ (Figure 5B). Terpenoids productivity increased significantly with increasing light intensity. The productivity of terpenoids in S. platensis was significantly different from the productivity in I. galbana and T. suecica, whereas productivity of terpenoids in I. galbana and T. suecica showed no significant differences (Figure 5C). 

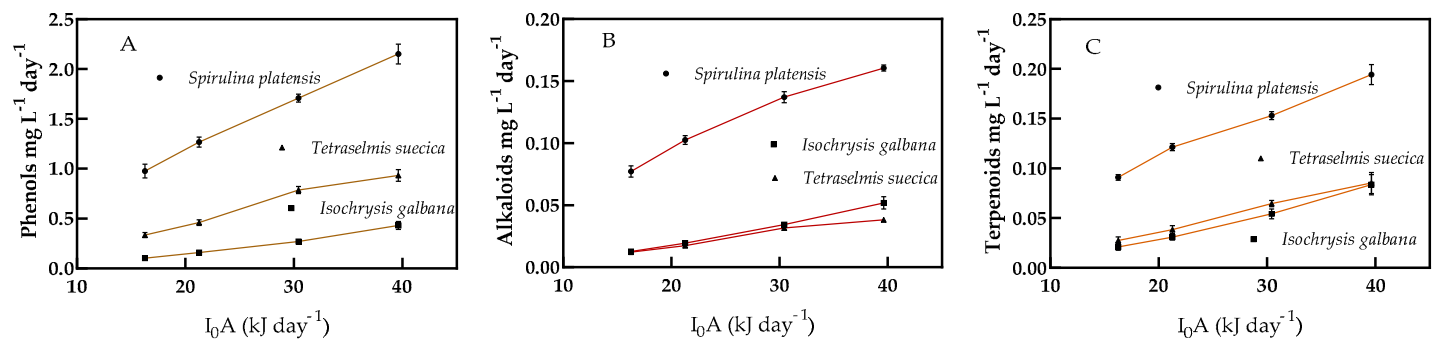

Figure 5. Phenols, alkaloids, and terpenoids productivities under continuous culture. (A) Phenols; (B) Alkaloids; (C) Terpenoids. At supplied light intensities (X axis) of 16.27, 21.26, 30.42, and $39.63 \mathrm{~kJ} \mathrm{~d}^{-1}$. Each point is the means of 3 replicates $(p<0.05)$.

Tocopherols content was significantly different in the four microalgae analyzed. T. suecica and P. cruentum showed higher amounts of tocopherols than S. platensis and I. galbana. In addition, tocopherols concentration increased with light intensity in the four microalgae (Table 7). Tocopherol concentration increased 1.22 times in P. cruentum to 1.56 times in I. galbana by changing light intensity from 16.27 to $39.63 \mathrm{~kJ} \mathrm{~d}^{-1}$.

Table 7. Tocopherols concentration. Tocopherols content of the four microalgae in continuous culture at different light intensities.

\begin{tabular}{|c|c|c|c|c|}
\hline $\mathbf{I}_{\mathbf{o}} \mathrm{A}$ & S. platensis & I. galbana & T. suecica & P. cruentum \\
\hline$\left(\mathrm{kJ} \mathrm{d}^{-1}\right)$ & \multicolumn{4}{|c|}{$\mu \mathrm{g}$ tocopherols $\mathrm{g}^{-1}$ biomass } \\
\hline 16.27 & $95.7^{\mathrm{a}}$ & $74.1^{\mathrm{e}}$ & $129.4^{\mathrm{i}}$ & $151.3^{\mathrm{m}}$ \\
\hline 21.26 & $101.1^{b}$ & $86.9^{\mathrm{f}}$ & $131.2^{\mathrm{j}}$ & $160.6^{n}$ \\
\hline 30.42 & $108.1^{\mathrm{c}}$ & $101.3^{g}$ & $150.2^{\mathrm{k}}$ & $180.1^{\circ}$ \\
\hline 39.63 & $120.5^{\mathrm{d}}$ & $115.5^{\mathrm{h}}$ & $159.8^{1}$ & $184.7^{\mathrm{p}}$ \\
\hline
\end{tabular}

All values are statistically different in the means of 3 replicates $(p<0.05)$.

Tocopherols productivity in S. platensis and P. cruentum was not significantly different at 16.27 and $21.26 \mathrm{~kJ} \mathrm{~d}^{-1}$ of light intensity supplied, but significant different when light intensity increased from 21.26 to $39.63 \mathrm{~kJ} \mathrm{~d}^{-1}$. P. cruentum showed a productivity increase of more than 1.2 times the productivity of S. platensis, 2.66 times the productivity of I. galbana, and 1.57 times the productivity of T. suecica (Figure 6).

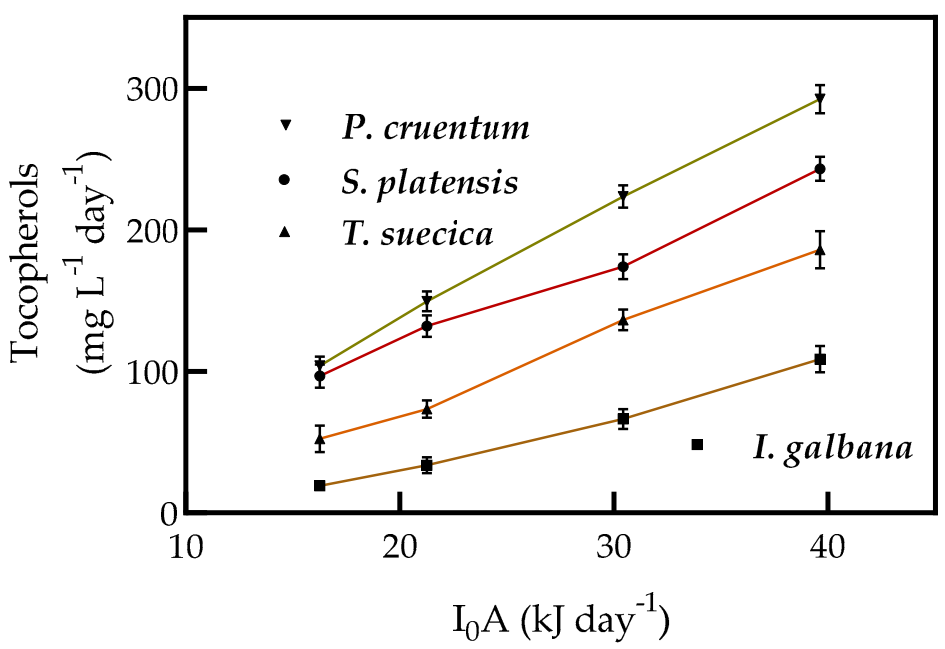

Figure 6. Tocopherols productivity in continuous cultures. Tocopherols productivity by S. platensis, I. galbana, T. suecica, and P. cruentum in continuous culture with different supplied light intensities $\left(16.27,21.26,30.42\right.$, and $\left.39.63 \mathrm{~kJ} \mathrm{~d}^{-1}\right)$. Each point represents the mean of 3 replicates $(p<0.05)$. 
The carotenoids content in the microalgae changed significantly from light intensities of 16.27 to $39.63 \mathrm{~kJ} \mathrm{~d}^{-1}$. Carotenoid content increased 1.5, 1.35, 1.56, and 1.57 times in S. platensis, I. galbana, T. suecica, and P. cruentum, respectively. At a light intensity of $39.63 \mathrm{~kJ} \mathrm{~d}^{-1}$, carotenoids content showed no significant differences among the microalgae studied (Table 8).

Table 8. Carotenoids content of the four microalgae analyzed in continuous culture at different supplied light intensities.

\begin{tabular}{ccccc}
\hline $\mathbf{I}_{\mathbf{o}} \mathbf{A}$ & S. platensis & I. galbana & T. suecica & P. cruentum \\
\hline $\mathbf{( k J ~ d ~}^{-1}$ ) & \multicolumn{5}{c}{${\text { (mg carotenoids } \mathbf{~ g}^{-\mathbf{1}} \text { biomass) }}$} \\
\hline 16.27 & $3.9^{\mathrm{a}}$ & $4.3^{\mathrm{b}}$ & $3.6^{\mathrm{a}}$ & $3.5^{\mathrm{a}}$ \\
21.26 & $4.2^{\mathrm{b}}$ & $5.3^{\mathrm{e}}$ & $4.6^{\mathrm{f}}$ & $4.5^{\mathrm{f}}$ \\
30.42 & $4.9^{\mathrm{c}}$ & $5.6^{\mathrm{d}}$ & $4.9^{\mathrm{c}}$ & $5.0^{\mathrm{c}}$ \\
39.63 & $5.9^{\mathrm{d}}$ & $5.8^{\mathrm{d}}$ & $5.6^{\mathrm{d}}$ & $5.5^{\mathrm{d}}$ \\
\hline
\end{tabular}

Identical letters in each column indicate no significant statistical difference in the means of 3 replicates $(p<0.05)$.

Carotenoids productivity changed with the biomass productivity for each microalga; S. platensis had a productivity at least twice that of I. galbana and T. suecica and at least 1.3 times that of P. cruentum (Figure 7). Carotenoids productivities in T. suecica and I. galbana were not significantly different at light intensities of 16.27 and $21.26 \mathrm{~kJ} \mathrm{~d}^{-1}$.

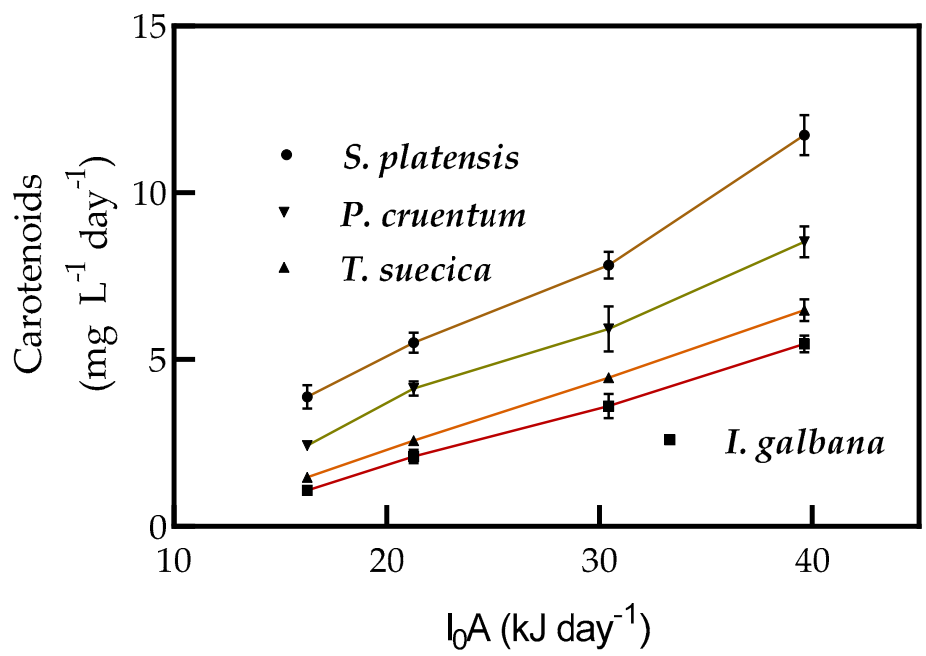

Figure 7. Carotenoids productivity of S. platensis, I. galbana, T. suecica, and P. cruentum in continuous culture under supplied light intensities of 16.27, 21.26, 30.42, and $39.63 \mathrm{~kJ} \mathrm{~d}^{-1}$. Each point indicates the mean of 3 replicates $(p<0.05)$.

The amounts of UA SOD were significantly different among S. platensis, I. galbana, and P. cruentum at different light intensities, but no difference was observed between S. platensis and T. suecica. SOD units increased significantly by increasing light intensity supplied in each microalga (Table 9).

The SOD UA productivity increased in accordance with biomass productivity with increasing

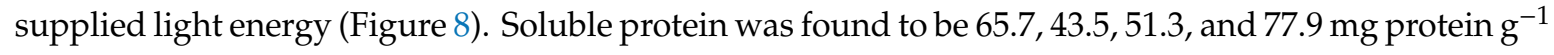
biomass for S. platensis, I. galbana, T. suecica, and P. cruentum, respectively. SOD UA productivity was significantly different in all microalgae. 
Table 9. UA of SOD in microalgae in continuous cultures at different light intensities.

\begin{tabular}{ccccc}
\hline $\mathbf{I}_{\mathbf{o}} \mathbf{A}$ & S. platensis & I. galbana & T. suecica & P. cruentum \\
\hline $\left.\mathbf{( k J ~ d ~}^{-1}\right)$ & \multicolumn{5}{c}{ UA SOD mg $\mathbf{~}^{-\mathbf{1}}$ protein } \\
\hline 16.27 & $45.7^{\mathrm{a}}$ & $29.1^{\mathrm{e}}$ & $48.8^{\mathrm{b}}$ & $68.2^{\mathrm{i}}$ \\
21.26 & $48.3^{\mathrm{b}}$ & $30.4^{\mathrm{f}}$ & $51.5^{\mathrm{c}}$ & $70.1^{\mathrm{j}}$ \\
30.42 & $50.4^{\mathrm{c}}$ & $33.2^{\mathrm{g}}$ & $53.2^{\mathrm{d}}$ & $71.9^{\mathrm{k}}$ \\
39.63 & $53.9^{\mathrm{d}}$ & $35.3^{\mathrm{h}}$ & $54.6^{\mathrm{d}}$ & $74.5^{\mathrm{l}}$ \\
\hline
\end{tabular}

Identical letters indicate no statistic differences in the means of 3 replicates $(p<0.05)$.

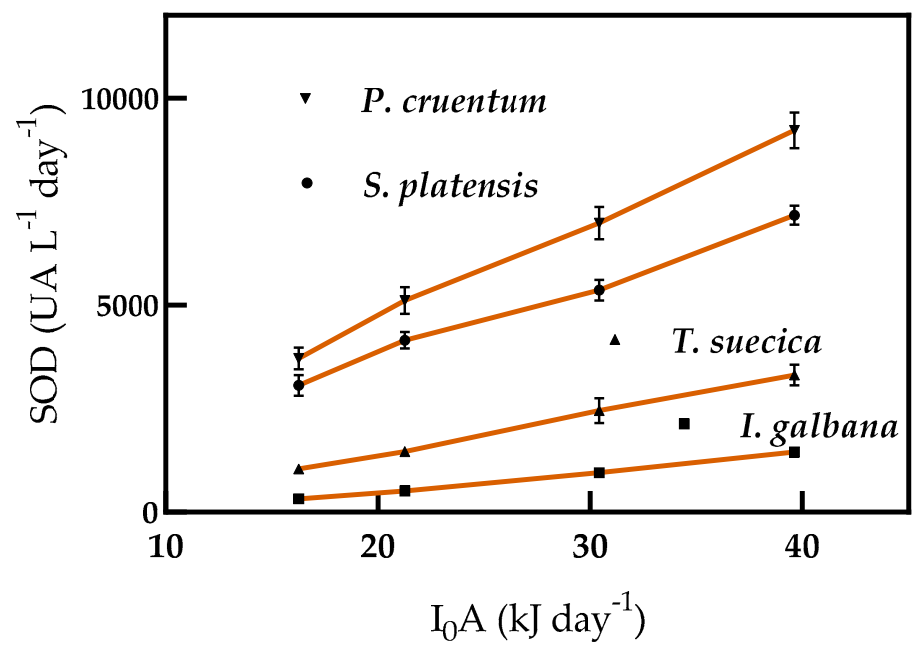

Figure 8. SOD productivity by S. platensis, I. galbana, T. suecica, and P. cruentum in continuous culture with different supplied light intensities. Each point indicates the mean of 3 replicates $(p<0.05)$.

Phycocyanin (PC) and allophycocyanin (APC) were found only in S. platensis and P. cruentum. Compared with the other antioxidants analyzed in this work, PC and APC content decreased with increasing light intensity (Table 10). PC concentration in S. platensis was 5.6 times the concentration in P. cruentum, and APC concentration in S. platensis was 7.1 times the concentration of APC in P. cruentum at a light intensity of $39.63 \mathrm{~kJ} \mathrm{~d}^{-1}$.

Table 10. PC and APC accumulation in S. platensis and P. cruentum in continuous cultures at different supplied light intensities.

\begin{tabular}{ccccc}
\hline $\mathbf{I}_{\mathbf{o}} \mathbf{A}$ & S. platensis & P. cruentum & S. platensis & P. cruentum \\
\hline $\mathbf{( k J ~ d ~}^{-1} \mathbf{)}$ & $\mathbf{m g ~ P C ~}^{\mathbf{- 1}}$ & biomass & mg APC $\mathbf{~ g}^{-\mathbf{1}}$ biomass \\
\hline 16.27 & 235 & 47 & 115 & 25 \\
21.26 & 217 & 42 & 102 & 17 \\
30.42 & 210 & 38 & 97 & 15 \\
39.63 & 198 & 35.4 & 92 & 13 \\
\hline
\end{tabular}

Different letters indicate statistically significant differences. All values are the means of 3 replicates $(p<0.05)$.

The PC production by S. platensis was 7.0 times that by P. cruentum; APC production of S. platensis was 8.9 times that of P. cruemtum (Figure 9). Although PC and APC content decreased with increasing light intensity, the production of both pigments increased with increasing light intensity due to biomass productivity. 

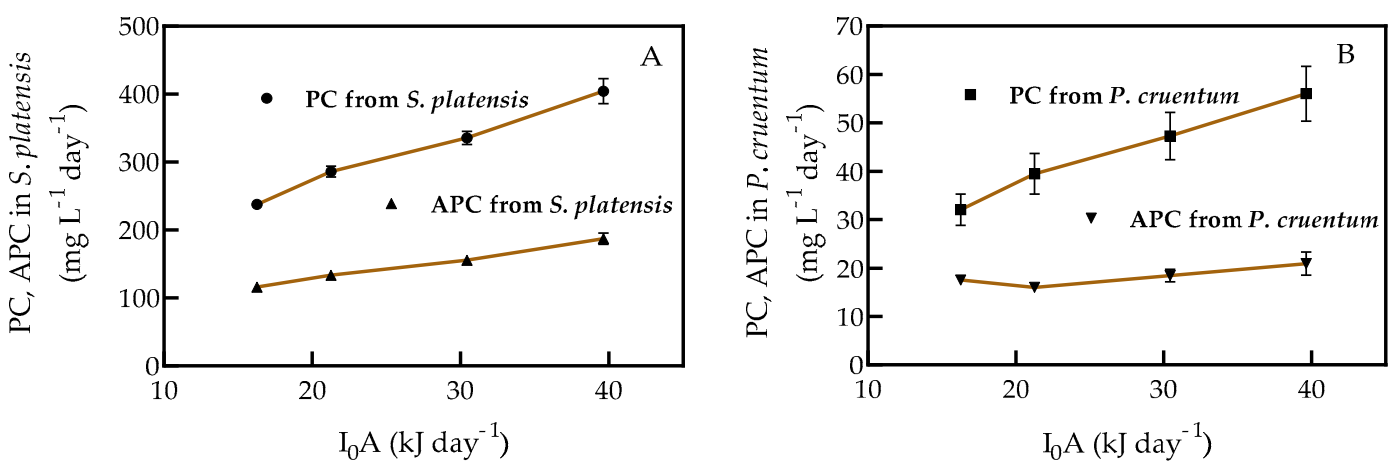

Figure 9. PC and APC production in (A) S. platensis and (B) P. cruentum under continuous cultures at different light intensities. Each point indicates the mean of 3 replicates $(p<0.05)$.

The extract of S. platensis was dissolved in solvent, then the extract was analyzed by FTIR (Table 11). Several signals appeared related to some characteristic vibrational groups. An important vibrational signal, the methylene group (2829-2848 $\mathrm{cm}^{-1}$ [22]), appeared at $2835 \mathrm{~cm}^{-1}$, which is possibly found in carotenoids and phytosterols molecules such as lycopene, which is a precursor of carotene [23]. Another vibrational signal found at $1230 \mathrm{~cm}^{-1}$ was assigned to the phenyl group and $1517 \mathrm{~cm}^{-1}$ to the stretching of the flavone phenyl ring; these signals correlate well with antioxidants such as flavone. The vibration band at $1740 \mathrm{~cm}^{-1}$ corresponds to the carbonyl group of phytosterols and the signal at $1612-1652 \mathrm{~cm}^{-1}$ to the $\mathrm{C}=\mathrm{O}$ group, which are signals assigned to ketones found in flavonoids.

Table 11. FTIR analyses of S. platensis extracts. Signal vibrations found in the S. platensis extract dissolved in solvents.

\begin{tabular}{cccc}
\hline Wave Number (cm $\mathbf{- 1})$ & Vibrational Signal & Attributed Chemical & $\begin{array}{c}\text { Peak Intensity } \\
\text { (Height-Width) }\end{array}$ \\
\hline 2947 & $v(\mathrm{C}-\mathrm{H})$ & methylene & short fine \\
2835 & $v(\mathrm{C}-\mathrm{H})$ & methylene group carotenoids & short fine \\
1740 & Carbonyl group & carbonyl group phytosterols & medium fine \\
1653 & $v(\mathrm{C}=\mathrm{O})$ & ketone & medium fine \\
1620 & $v(\mathrm{C}=\mathrm{O})$ & ketone & medium fine \\
1517 & $v_{\mathrm{S}}(\mathrm{C}=\mathrm{C})$ & flavone phenyl ring & medium fine \\
1452 & $v(\mathrm{C}=\mathrm{C})$ & aromatic & short medium \\
1409 & $v(\mathrm{C}=\mathrm{C})$ & aromatic & short fine \\
1230 & $v(\mathrm{C}-\mathrm{O}-\mathrm{C})$ & phenyl ether linkage & medium fine \\
1025 & $v(\mathrm{C}-\mathrm{H}), v(\mathrm{C}-\mathrm{O}-\mathrm{C})$ & ether & medium fine \\
948 & $v(\mathrm{C}-\mathrm{H})$ & methylene & medium fine \\
\hline
\end{tabular}

\section{Discussion}

The microalgae studied in this work exhibit reliance on antioxidant production on the growth conditions; however, strain species is an important factor. Antioxidant accumulation occurs along with cell growth, playing important roles in microalgal cells.

Phycocyanin has different biotechnological applications in cosmetics, food, and feed industries, analytical biochemistry, and therapeutic applications [19]. Zheng et al. [19] reported PC-protection against nephropathy by inhibiting oxidative stress, perhaps due to the similarity of the PC chemical structure with that of biliverdin. Chen et al. [20] reported a strategy to simultaneously improve biomass and PC productivities in a flat PBR with batch cultivation of 0.74 and $0.125 \mathrm{~g} \mathrm{~L}^{-1} \mathrm{~d}^{-1}$ under a light intensity of $700 \mu \mathrm{mol} \mathrm{m} \mathrm{m} \mathrm{s}^{-1}\left(32.95 \times 10^{-3} \mathrm{~kJ} \mathrm{~cm}^{-2} \mathrm{~h}^{-1}\right)$ [20], which is close to double the $15.1 \times 10^{-3} \mathrm{~kJ} \mathrm{~cm}^{-2} \mathrm{~h}^{-1}\left(320 \mu \mathrm{mol} \mathrm{m} \mathrm{m}^{-2} \mathrm{~s}^{-1}\right)$ light intensity used in the present work. Here, the biomass and PC productivities were 2 and $0.4 \mathrm{~g} \mathrm{~L}^{-1} \mathrm{~d}^{-1}$, respectively, which are 2.7 times the biomass and 3.2 times the PC productivity at $320 \mathrm{mmol} \mathrm{m}^{-2} \mathrm{~s}^{-1}$ compared to the values reported by Chen et al. [20] at 
$700 \mu \mathrm{mol} \mathrm{m}{ }^{-2} \mathrm{~s}^{-1}$. Although PC content in S. platensis was $235 \mathrm{PC} \mathrm{mg} \mathrm{g}^{-1}$ biomass at $132 \mu \mathrm{mol}$ photons $\mathrm{m}^{-2} \mathrm{~s}^{-1}$ and $198 \mathrm{PC} \mathrm{mg} \mathrm{g}{ }^{-1}$ biomass produced at $320 \mu \mathrm{mol} \mathrm{m} \mathrm{m}^{-2} \mathrm{~s}^{-1}$, PC productivity at $320 \mu \mathrm{mol}$ photons $\mathrm{m}^{-2} \mathrm{~s}^{-1}$ was 1.7 times the PC produced at $132 \mu \mathrm{mol} \mathrm{m} \mathrm{m}^{-2} \mathrm{~s}^{-1}$. Zheng et al. [19], in a PBR with a light intensity of $200 \mu \mathrm{mol} \mathrm{m} \mathrm{m}^{-2} \mathrm{~s}^{-1}$ in batch culture, obtained $0.39 \mathrm{~g} \mathrm{~L}^{-1} \mathrm{~d}^{-1}$ biomass productivity for S. platensis [19]. Schipper et al. worked with Leptolyngbya sp. to produce PC in continuous culture at $80 \mu \mathrm{mol}$ photons $\mathrm{m}^{-2} \mathrm{~s}^{-1}$. Under these conditions, $86 \mathrm{mg}$ of $\mathrm{PC}^{-1}$ biomass was produced with a productivity of $78.8 \mathrm{mg} \mathrm{L}^{-1} \mathrm{~d}^{-1}$ [24].

Microalgae produce important antioxidants: alkaloids, terpenoids, phenols, tocopherols, carotenoids, phycobilins, and other pigments and enzymes, which are involved in active antioxidant treatments due to their anti-inflammatory, antibacterial, and anticancer, lipid peroxidation activities. Porphyridium cruentum produced another promising compound, sulfate-polysaccharide, which has either anti-inflammatory or antiallergic properties. $\alpha$-tocopherol is the most abundant with the highest antioxidant activity in terrestrial plants; it functions in the electron transport reactions and cell membrane stabilization functions [25]. Animals are unable to synthesize tocopherols, so plant sources are a primary choice for human consumption. Nevertheless, microalgae have become a natural and alternative source of tocopherols, containing other tocopherols that provide remarkable synergistic antioxidant activity [18]. Durmaz et al. [21] reported 55.2 and $51.3 \mu \mathrm{g} \mathrm{g}^{-1}$ biomass of $\alpha$ and $\gamma$-tocopherol, respectively, in P. cruentum [21]. The amounts of $\alpha$ - and $\gamma$-tocopherols (80 and $104 \mu \mathrm{g} \mathrm{g}^{-1}$ biomass, respectively) in $P$. cruentum found in this study are in agreement with those reported by Durmaz et al. [21]. In addition, $\delta$-tocopherol was found in T. suecica, which produces $\gamma$-tocopherol in considerable amounts, but also produced $\alpha$-tocopherols. Spirulina maxima produces $\alpha$ and $\gamma$-tocopherols [18], but the amounts are lower than in S. platensis in this study.

Carotenoids and their derivative compounds bond to lipoproteins and play an important role as antioxidants during photosynthesis; they have been associated with potential protection against lipid peroxidation, DNA and protein oxidation, and in cancer prevention [8]. Photosynthetic organisms contain carotenoids; particularly in microalgae, $\alpha-$, and $\beta$-carotenes are present, whereas other microalgae are important axthasantin producers. The carotenoid content in microalgae rarely surpasses $10 \%$ and they are present as a mixture of carotenoids. In P. cruentum, Rebollo et al. [26] found $1.0 \mathrm{mg}$ $\mathrm{g}^{-1}$ biomass, whereas Santiago et al. reported $4.6 \mathrm{mg} \mathrm{g}^{-1}$ biomass for $\beta$-carotene in T. suecica [18].

SOD has been found in S. maxima, Nannochloropsis sp., T. suecica, Chaetoceros sp., Synechoccocus, and P. cruentum, with different amounts in each microalga. In T. suecica and P. cruentum, activities of 20.4 and $58 \mathrm{UA} \mathrm{mg}^{-1}$ protein were measured, respectively [18], in comparison with 54.6 and 74.5 $\mathrm{UA} \mathrm{mg}^{-1}$ protein reported in this work, respectively. The culture conditions may affect the formation of antioxidant compounds, in particular SOD; this enzyme may be induced in response to the increase or demand to drive reactive oxygen species generated by an increase in photosynthesis activity.

The FTIR spectra of $S$. platensis extracts showed vibrational signals related to some antioxidant molecules, such the signal at $2835 \mathrm{~cm}^{-1}$ assigned to the methylene group, at $1230 \mathrm{~cm}^{-1}$ to the phenyl group, the stretching at $1517 \mathrm{~cm}^{-1}$ assigned to the flavone phenyl ring, and the vibrational signals at $1612-1652 \mathrm{~cm}^{-1}$ assigned to the $\mathrm{C}=\mathrm{O}$ ketone groups found in flavonoids.

Microalgae extracts containing a mixture of antioxidants have the capacity to scavenge superoxide anions, hydrogen peroxides, and hydroxyl radicals [18]. The antioxidant machinery involves enzymatic and nonenzymatic antioxidants. These extracts also prevent oxidative damage by efficiently neutralizing free radicals, which includes catalase by the conversion of hydrogen peroxide into water and molecular oxygen. Other enzymes do not neutralize free radicals directly but create a reducing environment. Nonenzymatic antioxidants include vitamin $\mathrm{E}$, cofactor $\mathrm{Q}_{10}$, peptides (glutathione), phenols, and pigments [7]. All these antioxidants are synthesized in microalgae in different combinations and concentrations, highly dependent on strain, culture medium composition, time of harvesting, bioreactor geometry, and irradiated surface. The contents of antioxidants found in microalgae provide the possibility to focus efforts on obtaining reliable sources of antioxidants for production in biofactories. 


\section{Materials and Methods}

\subsection{Microalgae Strains, Culture Medium and Growth Conditions}

The microalgae Porphyridium cruentum, Isochrysis galbana, Tetraselmis suecica, and Spirulina platensis were acquired from our own culture collection of microalgae. For I. galbana, T. suecica, and P. cruentum, medium " $\mathrm{f}$ " [27] of Guillard and Ryther was used. S. platensis was grown on SOT standard medium [28]. Cultivation was performed in a jar-fermenter (Applikon Biotechnology BV, JG Delft, The Netherlands) equipped with 2 Rushton impellers $60 \mathrm{~mm}$ in diameter and a working volume of $1.0 \mathrm{~L}$. The top surface of the reactor (illuminated surface) had a surface area of $109.36 \mathrm{~cm}^{2}$ and diameter of $11.8 \mathrm{~cm}$. Light $(0.149$, $0.194,0.278$, and $0.36 \mathrm{Jcm}^{-2} \mathrm{~d}^{-1}$, with an irradiated surface of $109.36 \mathrm{~cm}^{2}$, producing $\mathrm{I}_{0} \mathrm{~A}=16.27,21.26$, 30.42 , and $39.63 \mathrm{~kJ} \mathrm{~d}^{-1}$, respectively) was supplied on the top of the bioreactor. The reactor was operated at a $30 \pm 2{ }^{\circ} \mathrm{C}$, agitation $200 \mathrm{rpm}$, and with an initial $\mathrm{pH}$ of 7.5 for Porphyridium cruentum, Isochrysis galbana, and Tetraselmis suecica, and $\mathrm{pH} 8.5$ for Spirulina platensis. The illumination was supplied with white light LED lamps on the top of the reactor. The photobioreactor was covered with aluminum foil, assuming that light filled the entire volume of the culture. The bioreactor was connected to a reservoir containing fresh medium; the flow rate was controlled by a valve. The fresh medium was fed into the bioreactor and the broth exit valve was open at the same flow rate. Dilution rate (D) was achieved after at least three days without changes in the cell density in the bioreactor, then the culture was considered in continuous mode or in a steady state. Cells were harvested by centrifugation at $12,000 \times g$ for $10 \mathrm{~min}$ at $4{ }^{\circ} \mathrm{C}$, then the collected biomass was kept at $-20^{\circ} \mathrm{C}$ if not used immediately. (Note: Conversions used: $1 \mathrm{lux}=1.55 \mu \mathrm{mol} \mathrm{m}{ }^{-2} \mathrm{~s}^{-1} ; 1 \mathrm{~cd}=10.76 \mathrm{lux} ; 1 \mathrm{~cd}=7.85 \times 10^{-6} \mathrm{~kJ} \mathrm{~cm}^{-2} \mathrm{~h}^{-1}$ ), ( $\mathrm{I}_{0} \mathrm{~A}$ is defined as the energy from light supplied to a surface area per unit of time).

\subsection{Quantitation of Phenols, Alkaloids, and Terpenoids}

S. platensis, I. galbana, and T. suecica biomass (0.1-0.5 g) were suspended in $5.5 \mathrm{~mL}$ of $0.01 \mathrm{M}$ phosphate buffer, $\mathrm{pH} 6.5$, and $0.15 \mathrm{M} \mathrm{NaCl}$. The suspension was frozen at $-20{ }^{\circ} \mathrm{C}$, thawed and sonicated, and then left at $5{ }^{\circ} \mathrm{C}$ overnight. The suspension was centrifuged at $12,000 \times \mathrm{g}$ for $15 \mathrm{~min}$ at $4{ }^{\circ} \mathrm{C}$; the supernatant was considered crude extract. Total alkaloids was measured as follows: The crude extract was mixed with chloroform $(1: 1 v / v)$ and the chloroform phase was separated and concentrated. The concentrate was resuspended with $1 \mathrm{~mL}$ of chloroform, and $6.26 \mathrm{~mL}$ of $\mathrm{H}_{2} \mathrm{SO}_{4}(0.02 \mathrm{~N})$ was added; chloroform was eliminated. Some drops of methyl red indicator were added into the solution, then the mixture was titrated with $\mathrm{NaOH}(0.02 \mathrm{~N})$. Each $\mathrm{mL}$ of $\mathrm{NaOH}(0.02 \mathrm{~N})$ added was equivalent to $5.78 \mathrm{mg}$ of alkaloids. Total phenols was measured as follows: $0.1 \mathrm{~mL}$ of the extract was mixed with $2.8 \mathrm{~mL}$ of deionized water, $2 \mathrm{~mL}$ of sodium carbonate ( $2 \%)$, and $0.1 \mathrm{~mL}$ of Folin-Ciocalteu reagent (50\%). The mixture was incubated for $30 \mathrm{~min}$ at room temperature and the absorbance of the mixture was recorded at $750 \mathrm{~nm}$ in a spectrophotometer [29]. Ferulic acid was used as the standard. For the determination of total terpenoids, $5 \mathrm{~mL}$ of extract was placed in an oven at $100{ }^{\circ} \mathrm{C}$ for $1 \mathrm{~h}$. After cooling, $5 \mathrm{~mL}$ of freshly prepared vanillin reagent $\left(0.7 \%\right.$ in $\left.65 \% \mathrm{H}_{2} \mathrm{SO}_{4}\right)$ was added. The tubes were heated at $60{ }^{\circ} \mathrm{C}$ in a water bath for $1 \mathrm{~h}$. After cooling on ice, the absorbance was measured at $473 \mathrm{~nm}$. Saponin was used as the standard. For FTIR analysis, an FTIR spectrometer (Frontier model, PerkinElmer, Waltham, MA, USA) was used; the sample was redissolved with a mixture of acetonitrile/methanol (70:30).

\subsection{Tocopherols and Carotenoids Determination}

Biomass (0.1-0.15 g) was mixed with a $2 \mathrm{~mL}$ solution containing $60 \%$ ethanol, pyrogallol (6\%), and $0.87 \mathrm{~mL} \mathrm{KOH}(60 \%)$ under $\mathrm{N}_{2}$ atmosphere, then it was sonicated. The mixture was incubated for $1 \mathrm{~h}$ at $70{ }^{\circ} \mathrm{C}$ in the dark, then the mixture was chilled on ice and $3.13 \mathrm{~mL}(\mathrm{NaCl} \%)$ was added and then extracted with $n$-hexane $(1: 1 v / v)$. The $n$-hexane was eliminated under $\mathrm{N}_{2}$. The concentrated extract was suspended in $0.7-1.0 \mathrm{~mL}$ of methanol and filtered through a $0.45 \mu \mathrm{m}$ membrane, the extract was filtered and stored at $-70{ }^{\circ} \mathrm{C}$. The methanolic extract was used to measure tocopherols in HPLC [18]. Twenty microliters of the extract were passed through a Zorbax XDB-C8 (4.6 mm $\times 150 \mathrm{~mm}, 5 \mu \mathrm{m}$; Agilent 
Technologies, Santa Clara, CA, USA) column and eluted with an isocratic solution of methanol/water (95:05) at a flow rate of $1.0 \mathrm{~mL} \mathrm{~min}{ }^{-1}$. A fluorescence detector using an excitation $\lambda_{292}$, an emission wavelength of $\lambda_{340}$, and a UV detector at $\lambda_{340}$ were used to measure the tocopherols content [18]. Commercial $\alpha, \delta$, and $\gamma$-tocopherols served as the standards for quantification and detection. Total carotenoids were measured at $480 \mathrm{~nm}\left(\mathrm{~A}_{1 \%}=2500\right.$ absorption coefficient $)$ of absorbance in a UV-Vis spectrophotometer [30].

\subsection{Superoxide Dismutase Activity Determination}

We mixed 0.05 to $0.1 \mathrm{~g}$ of biomass with $1 \mathrm{~mL}$ phosphate buffer $(0.2 \mathrm{M}, \mathrm{pH}$ 8.0, $5 \mathrm{mM}$ EDTA, $1 \mathrm{mM}$ DTT), sonicated for $2 \mathrm{~min}$, then centrifuged at $12,000 \times g$ at $4{ }^{\circ} \mathrm{C}$ for $30 \mathrm{~min}$. The supernatant was used for measurements or stored frozen. For SOD activity determination, the Bioxytech SOD-525 assay kit (Oxis International, Foster, CA, USA) was used. The reaction was followed at $525 \mathrm{~nm}$ at $30^{\circ} \mathrm{C}$ for $1 \mathrm{~min}$. The reaction contained $50 \mu \mathrm{g}$ protein $\mathrm{mL}^{-1}$ of extract. Commercial SOD was used as the standard. Protein content was measured using Bio-Rad reagent (Bio-Rad Laboratories, Inc., Berkeley, CA, USA) at $595 \mathrm{~nm}$ in a spectrophotometer [18].

\section{5. $P C$ and APC Determinations}

S. platensis and P. cruentum biomass (0.1-0.5 g) was suspended in $5.5 \mathrm{~mL}$ of potassium phosphate buffer $0.01 \mathrm{M}, \mathrm{pH} 6.5$, and $0.15 \mathrm{M} \mathrm{NaCl}$. The suspension was frozen at $-20^{\circ} \mathrm{C}$, thawed, and sonicated, then left at $5{ }^{\circ} \mathrm{C}$ overnight. The suspension was centrifuged at $12,000 \times \mathrm{g}$ for $15 \mathrm{~min}$ at $4{ }^{\circ} \mathrm{C}$. The supernatant contained phycocyanin-allophycocyanin extract. Phycocyanin and allophycocyanin concentrations were calculated according to Bennet and Bogard [31] by measuring the absorbance at 615 and $652 \mathrm{~nm}$ in a spectrophotometer and applying the following equations (data in $\mathrm{mg} \mathrm{mL}^{-1}$ ): where $\mathrm{OD}=$ optical density

$$
\begin{gathered}
\mathrm{PC}=\frac{O D_{615}-0.474\left(O D_{652}\right)}{5.34} \\
\mathrm{APC}=\frac{O D_{652}-0.208\left(O D_{615}\right)}{5.09}
\end{gathered}
$$

\subsection{Statistical Analyses}

GraphPad Prisma software version 8.4.3 (GraphPad Software, San Diego, CA, USA) was used for all analyses. For growth, the Gompertz model was used to calculate growth parameters. For biomass productivity at different light intensities, a linear regression analysis was applied and we compared the 4 strains. To compare the concentration and productivity of all strains at different light intensities, Tukey's multiple comparison test was applied $(p<0.05)$.

\section{Conclusions}

Microalgae, including cyanobacteria, are manipulatable organisms that grow in photobioreactors, where the medium composition, light intensity, reactor design, reactor operation, metabolism, and microalga species are important factors affecting the production of compounds synthesized by the microalgae. In this work, well-known microalgae species that produce secondary metabolites were assayed for the production of different compounds that have remarkable antioxidant activity. We found that the microalgae produce a mixture of antioxidants in different amounts depending on the species, light supplied, and bioreactor operation. Phenols, alkaloids, terpenoids, tocopherols, carotenoid, PC, and APC content, including an enzyme, SOD, were produced by the microalgae tested. Continuous bioreactor operation substantially improved biomass and antioxidant productivity in comparison with batch cultivation in the same bioreactor under the same conditions, except that continuous cultivation produces the same amount of biomass and secondary metabolites every day over nine days of cultivation as achieved in batch cultures. Continuous cultivation drives the microalgal cell metabolism of biomass and metabolites synthesis in the bioreactor; the mathematical description 
of continuous cultivation is referred to as a steady state, where biochemical pathways constantly dynamically synthesize molecules. Antioxidants are produced naturally as a mixture. We deduced that the combination of continuous culture with the correct nutrient limitation will improve or enhance the production of a specific antioxidant, but this may limit the production of other antioxidants.

Author Contributions: J.F.L.-H.: Conceptualization, investigation, methodology; D.P.-R.: Writing-Review and editing; C.A.Á.-G.: conceptualization, methodology; P.G.-A., data curation and analyses, Writing-Original draft preparation; J.C.P.-R., formal analyses, methodology; F.J.M.-R., Writing-Original draft preparation, conceptualization, methodology, formal analysis, resources, Writing-Review and editing, supervision, funding acquisition. All authors have read and agreed to the published version of the manuscript.

Funding: This research was funded by the Instituto Politécnico Nacional, grant number: 1947 Proyecto de Investigación 2020. This publication was supported by Comisión de Operación y Fomento de Actividades Académicas (COFAA) del Instituto Politécnico Nacional.

Acknowledgments: The authors are grateful for the financial support from Consejo de Ciencia y Tecnología del Estado de Tabasco. The authors thank Mauricio Ramos López for their technical support.

Conflicts of Interest: The authors declare no conflict of interest.

\section{References}

1. Kothari, R.; Pandey, A.; Ahmad, S.; Kumar, A.; Pathak, V.V.; Tyagi, V.V. Microalgal cultivation for value-added products: A critical enviro-economical assessment. 3 Biotech 2017, 7, 243. [CrossRef]

2. Muller-Feuga, A. Microalgae for Aquaculture: The Current Global Situation and Future Trends. In Handbook of Microalgal Culture, 2nd ed.; Richmond, A., Hu, Q., Sons, W., Eds.; Wiley: Chichester, UK, 2013; pp. 613-627.

3. Abd El-Hack, M.E.; Abdelnour, S.; Alagawany, M.; Abdo, M.; Sakr, M.A.; Khafaga, A.F.; Mahgoub, S.A.; Elnesr, S.S.; Gebriel, M.G. Microalgae in modern cancer therapy: Current knowledge. Biomed. Pharmacother. 2019, 111, 42-50. [CrossRef] [PubMed]

4. Roy, S.S.; Pal, R. Microalgae in Aquaculture: A Review with Special References to Nutritional Value and Fish Dietetics. Proc. Zool. Soc. 2015, 68, 1-8. [CrossRef]

5. Karawita, R.; Senevirathne, M.; Athukorala, Y.; Affan, A.; Lee, Y.-J.; Kim, S.-K.; Lee, J.-B.; Jeon, Y.-J. Protective Effect of Enzymatic Extracts from Microalgae Against DNA Damage Induced by $\mathrm{H}_{2} \mathrm{O}_{2}$. Mar. Biotechnol. 2007, 9, 479-490. [CrossRef]

6. Singh, S.; Kate, B.N.; Banerjee, U.C. Bioactive Compounds from Cyanobacteria and Microalgae: An Overview. Crit. Rev. Biotechnol. 2005, 25, 73-95. [CrossRef] [PubMed]

7. Shebis, Y.; Iluz, D.; Kinel-Tahan, Y.; Dubinsky, Z.; Yehoshua, Y. Natural Antioxidants: Function and Sources. Food Nutr. Sci. 2013, 4, 643-649. [CrossRef]

8. Lordan, S.; Ross, R.P.; Stanton, C. Marine Bioactives as Functional Food Ingredients: Potential to Reduce the Incidence of Chronic Diseases. Mar. Drugs 2011, 9, 1056-1100. [CrossRef] [PubMed]

9. Li, K.; Li, X.-M.; Ji, N.-Y.; Wang, B.-G. Natural bromophenols from the marine red alga Polysiphonia urceolata (Rhodomelaceae): Structural elucidation and DPPH radical-scavenging activity. Bioorg. Med. Chem. 2007, 15, 6627-6631. [CrossRef]

10. MacArtain, P.; Gill, C.I.R.; Brooks, M.; Campbell, R.; Rowland, I.R. Nutritional Value of Edible Seaweeds. Nutr. Rev. 2007, 65, 535-543. [CrossRef]

11. Hu, C.-C.; Lin, J.-T.; Lu, F.-J.; Chou, F.-P.; Yang, D.-J. Determination of carotenoids in Dunaliella salina cultivated in Taiwan and antioxidant capacity of the algal carotenoid extract. Food Chem. 2008, 109, 439-446. [CrossRef]

12. Cha, K.H.; Lee, H.J.; Koo, S.Y.; Song, D.-G.; Lee, D.-U.; Pan, C.-H. Optimization of Pressurized Liquid Extraction of Carotenoids and Chlorophylls from Chlorella vulgaris. J. Agric. Food Chem. 2010, 58, 793-797. [CrossRef] [PubMed]

13. Bocanegra, A.; Bastida, S.; Benedí, J.; Ródenas, S.; Sánchez-Muniz, F.J. Characteristics and Nutritional and Cardiovascular-Health Properties of Seaweeds. J. Med. Food 2009, 12, 236-258. [CrossRef] [PubMed]

14. Halliwell, B. Biochemistry of oxidative stress. Biochem. Soc. Trans. 2007, 35, 1147-1150. [CrossRef] [PubMed]

15. Brewer, M.S. Natural Antioxidants: Sources, Compounds, Mechanisms of Action, and Potential Applications. Compr. Rev. Food Sci. Food Saf. 2011, 10, 221-247. [CrossRef] 
16. Bong, S.C.; Loh, S.P. A study of fatty acid composition and tocopherol content of lipid extracted from marine microalgae, Nannochloropsis oculata and Tetraselmis suecica, using solvent extraction and supercritical fluid extraction. Int. Food Res. J. 2013, 20, 721-729.

17. Niemczyk, E.; Żyszka-Haberecht, B.; Drzyzga, D.; Lenartowicz, M.; Lipok, J. Algae in Biotechnological Processes. In Algae Biomass: Characteristics and Applications: Towards Algae-Based Products; Chojnacka, K., Wieczorek, P.P., Schroeder, G., Michalak, I., Eds.; Springer: Cham, Switzerland, 2018; pp. 33-48.

18. Santiago-Morales, I.S.; Trujillo-Valle, L.; Márquez-Rocha, F.J.; López Hernández, J.F. Tocopherols, Phycocyanin and Superoxide Dismutase from Microalgae: As Potential Food Antioxidants. Appl. Food Biotechnol. 2018, 5, 19-27. [CrossRef]

19. Zheng, J.; Inoguchi, T.; Sasaki, S.; Maeda, Y.; McCarty, M.F.; Fujii, M.; Ikeda, N.; Kobayashi, K.; Sonoda, N.; Takayanagi, R. Phycocyanin and phycocyanobilin from Spirulina platensis protect against diabetic nephropathy by inhibiting oxidative stress. Am. J. Physiol. Regul. Integr. Comp. Physiol. 2013, 304, R110-R120. [CrossRef]

20. Chen, C.-Y.; Kao, P.-C.; Tsai, C.-J.; Lee, D.-J.; Chang, J.-S. Engineering strategies for simultaneous enhancement of C-phycocyanin production and $\mathrm{CO}_{2}$ fixation with Spirulina platensis. Bioresour. Technol. 2013, 145, 307-312. [CrossRef] [PubMed]

21. Durmaz, Y.; Monteiro, M.; Bandarra, N.; Gökpinar, Ş.; Işik, O. The effect of low temperature on fatty acid composition and tocopherols of the red microalga, Porphyridium cruentum. J. Appl. Phycol. 2007, 19, 223-227. [CrossRef]

22. Manthey, J.A. Fourier Transform Infrared Spectroscopic Analysis of the Polymethoxylated Flavone Content of Orange Oil Residues. J. Agric. Food Chem. 2006, 54, 3215-3218. [CrossRef]

23. Bunghez, R.; Raduly, M.; Doncea, S.; Akasahin, I.; Ion, R.M. Lycopene determination in tomatoes by different spectral techniques (UV-VIS, FTIR and HPLC). Dig. J. Nanomater. Biostruct. 2011, 6, 1349-1356.

24. Schipper, K.; Fortunati, F.; Oostlander, P.C.; Al Muraikhi, M.; Al Jabri, H.M.S.J.; Wijffels, R.H.; Barbosa, M.J. Production of phycocyanin by Leptolyngbya sp. in desert environments. Algal Res. 2020, 47, 101875. [CrossRef]

25. Carballo-Cárdenas, E.C.; Tuan, P.M.; Janssen, M.; Wijffels, R.H. Vitamin E (alpha-tocopherol) production by the marine microalgae Dunaliella tertiolecta and Tetraselmis suecica in batch cultivation. Biomol. Eng. 2003, 20, 139-147. [CrossRef]

26. Rebolloso Fuentes, M.M.; Acién Fernández, G.G.; Sánchez Pérez, J.A.; Guil Guerrero, J.L. Biomass nutrient profiles of the microalga Porphyridium cruentum. Food Chem. 2000, 70, 345-353. [CrossRef]

27. Guillard, R.R.; Ryther, J.H. Studies of marine planktonic diatoms. I. Cyclotella nana Hustedt, and Detonula confervacea (cleve) Gran. Can. J. Microbiol. 1962, 8, 229-239. [CrossRef]

28. Ogawa, T.; Terui, G. Studies on the growth of Spirulina platensis. on the pure culture of Spirulina platensis. J. Ferment. Technol. 1970, 48, 361-367.

29. Shanab, S.M.M.; Mostafa, S.S.M.; Shalaby, E.A.; Mahmoud, G.I. Aqueous extracts of microalgae exhibit antioxidant and anticancer activities. Asian Pac. J. Trop. Biomed. 2012, 2, 608-615. [CrossRef]

30. Marquez, F.J.; Sasaki, K.; Kakizono, T.; Nishio, N.; Nagai, S. Growth characteristics of Spirulina platensis in mixotrophic and heterotrophic conditions. J. Ferment. Bioeng. 1993, 76, 408-410. [CrossRef]

31. Bennett, A.; Bogorad, L. Complementary chromatic adaptation in a filamentous blue-green alga. J. Cell Biol. 1973, 58, 419-435. [CrossRef]

Sample Availability: Samples of the compounds are not available from the authors 